\title{
An evaluation of a logbook for trainees in accident and emergency medicine in the United Kingdom
}

\author{
C. LUKE, E. KADZOMBE, A. ARMSTRONG, \\ D. GORMAN \& J. HORNER
}

Merseyside Group of Senior Registrars in Accident and Emergency Medicine

\section{SUMMARY}

The ideal requirements of a logbook for trainees in accident and emergency medicine in the United Kingdom were sought by means of a postal survey of 100 Senior Registrars and recently-appointed Consultants in the specialty. Sixty-two replies were received. An overwhelming majority supported ACLS and ATLS certification, as well as formal training in Management/Clinical Budgeting skills, the use of Information Technology, dealing with medicolegal issues and Disasteo Planning. Secondments to General Practice, Regional Poisons Centres and the Emergency Services were similarly recommended. A total of $71 \%$ (42 responders approved of a minimum of 3 years experience in an A\&E Department before appointment as a Senior Registrar in the specialty. The majority of responders disapproved of acquiring laboratory-based skills. The results of the survey are discussed and suggestions for the possible role of a logbook are made.

\section{INTRODUCTION}

Logbooks are a well-established part of training in some specialties, most notably, in General Surgery and Obstetrics, where they indicate ideal targets for training to both the trainee and his/her trainer. Recent debate among British medical educators has led to increasing interest in the inclusion of logbooks within all higher medical training programmes (Johnson, 1989). Emergency Medicine training in the U.S.A. and Australasia, is based on curricula and study-guides produced by the National Colleges of Emergency Medicine and affiliated organizations (ACEM, 1986; Asch et al., 1986; Tintinalli et al., 1988; Swor et al., 1989) In the United Kingdom, no such curricula exist and training in A\&E is based on guidelines

Correspondence: C. Luke, Senior Registrar, AEE Department, Royal Liverpool Hospital, Liverpool L7 8XP 
laid down by the Specialist Advisory Committee (SAC) for Accident and Emergency Medicine. These guidelines provide for a series of clinical and other secondments that aim to supplement the SR's previous training (which has often been in another specialty). Although previous assessments found that such a training was broadly satisfactory to U.K. trainees, a number of recurrent controversies regarding content, format and timing were identified (Miles, 1983; Driscoll et al., 1988). We carried out this study: (1) to identify the main areas of controversy; (2) to ascertain whether a curriculum for $A \& E$ training could be devised and; (3) to assess whether a logbook might facilitate the monitoring of such a curriculum.

\section{MATERIALS AND METHODS}

A questionnaire, devised to simulate a hypothetical logbook for A\&E trainees, was posted to 100 Senior Registrars and recently-appointed (i.e. within 3 years) Consultants in Accident and Emergency Medicine. A stamped, addressed envelope was included to facilitate replies. The AEE Logbook was an eclectic invention of the Group and was founded on personal experiences. There were 34 sections in the questionnaire and these related to most medical and surgical specialties, resuscitation skills and non-clinical areas e.g. management training, medical illustration and disaster planning. A final section concerned the 'recommended minimum' amount of experience in A\&E practice before appointment as Senior Registrar. The responders were invited to agree or disagree with the hypothetical requirements of the $A \mathcal{E} E$ Logbook and, if inclined, suggest their own ideal numbers or time to be spent in exposure to different clinical and non-clinical activities. A free space was allocated for general comments.

\section{RESULTS}

Of 100 clinicians who received questionnaires, $62(62 \%)$ replied. This constitutes an average response to a postal survey. One responder declined to fill in the questionnaire because of his opposition to the principle of 'skill-based', as opposed to 'time-based', training. The predominant elements of the hypothetical logbook are tabulated (Tables $1 \& 2$ ) according to support among responders. A total of $35(55.5 \%)$ of responders disagreed with the notion of specific figures for procedures learned and clinical experience; nevertheless, most agreed in principle with a broadly-based and demonstrable training programme. A considerable number of comments and ideas were proposed: in summary, these recommended that while training should encompass a great variety of clinical and non-clinical skills, the training should be flexible and practicable e.g. paediatric resuscitation experience, thoracotomy and Sengstaken tube placement, while eminently desirable, were hard-won skills even in 'Regional Centres of Excellence'.

'Expertise in everything' was eschewed, hands-on experience was deemed most 
Table 1 Support for clinical skills training targets

over $90 \%$ :

A.C.L.S. and A.T.L.S. certification, simple fracture/dislocation reduction, central venous cannulation, slit lamp examination, management training and budgeting, disaster planning, giving evidence and other medicolegal activities, computer literacy? and use of information technology.

over $60 \%$ :

General anaesthesia, Bier's and Femoral nerve block, thoracotomy/thoracostomy, plaster application, joint aspiration, use of vaginal speculum, simple skin grafting, halo-traction application, suture of bleeding dental socket, dental anaesthesia, gastric lavage, pericardiocentesis.

over $40 \%$ :

Pedal and forearm nerve block, medical illustration i.e. preparation of slides etc.

Table 2 Support for secondment targets

over $90 \%$ : Ambulance, Police and Fire Services, General Practice, Regional Poisons Centre.

over $60 \%$ : Anaesthesia, Intensive Therapy and Coronary Care units, Paediatric General Anaesthesia, Intensive Therapy and Coronary Care units, Paediatric General Medicine/Surgery, Plastic and Maxillofacial surgery, Ophthalmology and Otorhinolaryngology, Gynaecology, Dermatology, Geriatric Medicine, Radiology.

over $40 \%$ :

Autopsies, Peripheral Vascular Clinics, Gastrointestinal Wards, Rheumatology Wards, $\stackrel{\bullet}{\oplus}$ Dermatology Wards, Urology Wards, Endocrinology Clinics, Cardiac Catheterization.

Dermatology Wards, Urology Wards, Endocrinology Clinics, Cardiac Catheterization.e

worthwhile and 'esoteric techniques', e.g. skin biopsy, urethral dilatation or electro- $-\frac{0}{-}$ physiology, were rejected. Most clinicians believed that the bulk of skills and $\overrightarrow{\vec{O}}$ experiences included in the hypothetical logbook should be acquired before appointment as a Senior Registrar (SR) in Accident and Emergency Medicine.

Prolonged experience (i.e. at least 2 years) as an SR within one or more A\&E Department acquiring managerial and budgeting skills was widely felt to be $e^{3}$. more important than gaining clinical skills that would be better cultivated as as junior or middle-grade clinician. Additional skills and experiences that were noto mentioned in the theoretical agenda but were proposed by responders included $\beta$ overseas exchange posting, cricothyroidotomy and external cardiac pacing. Forty-o two $(71 \%)$ of responders approved of a minimum of 3 years A\&E experiences before appointment as $S R$ in the specialty. Five correspondents disapproved vehemently of the whole idea of a logbook (or 'tickbook' as one described it). They believed in essence that the logbook concept 'fudged the real issue'. This was the need for all in the specialty to establish the ideal role of the Consultant in N A\&E Medicine and his or her proper objectives: 'to offer an improved level of careo at that unattractive and inconvenient and disruptive point of first contact betweeno the medical world and the world out there... and to continually guard against the risk of creating a second-rate pseudo-specialist service'. 
The present Specialist Advisory Committee (SAC) guidelines for Higher Specialist Training in A\&E Medicine in the U.K. prescribe a widely-based general professional training and higher qualification in General Medicine, Surgery, Anaesthesia or the Fellowship in Accident and Emergency Medicine from the Royal College of Surgeons of Edinburgh. General experience at a Registrar level in an A\&E Department is recommended before appointment as a Senior Registrar; the training of the SR is then 'individually tailored' according to previous experience and seeks to include 2 years in one or more A\&E departments with broad clinical and administrative experience. This is followed by or interspersed with 3-month full-time attachments in Paediatrics, General Medicine with Cardiology, Anaesthesia with Intensive Care, General Surgery and Orthopaedics if the trainee has not been exposed previously to these disciplines at a responsible level with adequate supervision and for at least 3 months'. Shorter attachments are suggested in Acute Psychiatry, Neurosurgery, Plastic Surgery, General Practice and 'other specialties considered specifically appropriate for the trainee'. Other recommendations include experience in research projects, work with the Emergency Services, Community Welfare services, Health Education and accident prevention agencies. Despite these recommendations, there is considerable variation in the constitution of Training Programmes for SRs in A\&E throughout the UK and it would appear that few of these programmes fulfil the ideals of the SAC. More importantly, perhaps, we have discovered considerable discrepancy in the perception of existing training requirements, along with considerable differences in opinion among the trainees about the 'ideal end-product'. The controversies identified by this and the previous study of Driscoll et al. (1988) undoubtedly reflect the varying background of A\&E Senior Registrars. Nevertheless, it appears from this study that a consensus is developing in relation to the future direction of Accident and Emergency Medicine in the U.K. A 'core-curriculum' emphasizing Advanced Trauma and Cardiac Life Support, practical clinical skills, secondments to the Emergency Services and Poisons Centres and formal Management Training is emerging. The limitations and advantages of logbooks have been well-described. They have been criticized for being time-consuming, for being capable of misuse and for reducing flexibility in training; nonetheless, there is increasing belief in documenting 'what is anticipated and what is experienced by way of service and education, and highlighting both the good and the bad' (King, 1989). Given the current controversy about the timing, the form and the content of training in A\&E Medicine in the U.K, a logbook may well be the ideal catalyst of change. It could be used experimentally to record actual SR training and then employed by trainee and trainer to establish agreed targets based on the sort of curriculum advocated by the findings of this and similar studies. With the qualified support for logbooks provided by this study and by contemporary postgraduate educators (Johnson, 1989; King, 1989), there seems to be good reason for trying out a prototype in one or more A\&E Senior Registrar training programmes. The specialty of Accident and Emergency Medicine in the U.K. is coming of age and is preparing to create its own governing Faculty. One of its most pressing tasks will surely be to produce an appropriate 
and acceptable curriculum for the training of the future A\&E specialist. 'It may be $\mathrm{T}$ a pious hope that logbooks will improve this complicated process; they could $\frac{\Phi}{0}$ hardly make it worse'.

(The Merseyside Group is planning to canvas Senior A\&E Specialists on their attitude towards a formalized A\&E curriculum and the value of a logbook in implementing such a curriculum.)

\section{ACKNOWLEDGEMENT}

The advice and guidance of Mr Nigel Brayley, Miss Sheila Christian, Dr Elizabeth $\stackrel{\vec{\circ}}{\vec{H}}$ Molyneaux, Dr Trevor Bayley and Dr Keith Little, in preparing this paper, is $\vec{\omega}$ gratefully acknowledged.

\section{REFERENCES}

Asch S., \& Weigand J. (1986) A Pediatric Curriculum for Emergency Medicine Training Programs. Annals of Emergency Medicine 13 (1), 19-27.

The Australasian College for Emergency Medicine. (1986) Training and Examination Handbook.

Driscoll P., Cope A. \& Miles A. D. (1988) Adequacy of Senior Registrar Training in Accident and 6

Emergency Medicine over the last 5 Years. Archives of Emergency Medicine 5 (3), 162-8.

Johnson R. (1989) Do Politicians understand the needs of Postgraduate Medicine? British Journal Hospital Medicine 42, 422-3.

Joint Committee on Higher Medical Training. (1988/89) Training Handbook.

King R. C. (1989) A Logbook for Preregistration House Officers (Editorial) British Journal of Hospital Medicine 41, 111.

Miles S. (1983) The Senior Registrar Training Programme. British Journal of Accident and Emergency Medicine 1 (3), 4-5.

Swor R. A., Chisholm C. \& Krohmer J. (1989) Model Curriculum in Emergency Medical Services for Emergency Medicine Residencies. Annals of Emergency Medicine 18 (4), 418-21.

Tintinalli J. E., Krome R. L. \& Ruiz E. (Eds). (1988) Emergency Medicine: A Comprehensive Study Guide. American College of Emergency Physicians. McGraw-Hill Book Company, New York. 